\title{
DAMPAK PERUBAHAN IKLIM TERHADAP USAHA APEL DI KECAMATAN PONCOKUSUMO KABUPATEN MALANG
}

\author{
Juli Rahaju ${ }^{1)}$, Muhandoyo ${ }^{2)}$ \\ Fakultas Pertanian, Universitas Wisnuwardhana \\ ji_joely@yahoo.com \\ Fakultas Pertanian, Universitas Wisnuwardhana \\ Muhandoyoir@gmail.com
}

\begin{abstract}
Climate change has a significant impact in the fields of agriculture, because agriculture has a heavy reliance on climate elements. Therefore, studies on the impact of climate change on agriculture is important to study. This case study was conducted in Poncokusumo, Malang Regency for 7 months. Subjects were apple growers who have made apple cultivation for 10 years or more and still trying to apple today. The research object is climate change with the elements that will be Studied include temperature, humidity and rainfall and Adaptation Efforts that have been done the farmer. The results Showed that both climatic elements of temperature, humidity and rainfall simultaneously Contribute Significantly to the productivity of the apple. Separately rainfall only significant role. Respondents who did the adaptation as much as $85.29 \%$ of the total respondents. Form of adaptation by farmers are watering the plants to cope with high temperatures, intercropping to address the decline in income from apples, the reduction of more branches to cope with the humidity and spraying pesticides more intensively to address the incidence of diseases by the caused by rainfall and high humidity.
\end{abstract}

Keywords : Impacts, Climate Change, Business Apples

Beberapa tahun terakhir ini telah terjadi penurunan produksi apel di Kota Malang Raya yang memiliki 2 sentra apel yaitu Batu dan Poncokusumo. Menurunnya produksi apel disebabkan banyak petani yang gagal panen akibat perubahan cuaca. Hasil panen saat ini jauh dari hasil panen saat kondisi cuaca normal. Petani apel menilai bahwa kegagalan panen beberapa tahun ini disebabkan terjadinya hujan yang terus menerus (Setiawan, 2011).

Besar kecilnya dampak perubahan iklim terhadap pertanian sangat bergantung pada tingkat dan laju perubahan iklim di satu sisi serta sifat dan kelenturan sumber daya dan sistem produksi pertanian di sisi lain. Oleh sebab itu petani harus lebih peka dan lebih cerdik dalam mengelola usahataninya. Mereka harus bisa menyesuaikan sistem produksinya dengan beradaptasi dengan kondisi iklim yang tidak menentu sehingga kehilangan hasil produksi dapat diminimalisir.
Berdasarkan permasalahan tersebut, maka penelitian ini diarahkan untuk mengkaji bagaimanakah unsur-unsur perubahan iklim yaitu curah hujan, suhu dan kelembaban berperan terhadap produktivitas apel dan bagaimana upaya adaptasi yang sudah dilakukan para petani apel di Kecamatan Poncokusumo Kabupaten Malang terhadap perubahan iklim.

\section{METODE PENELITIAN}

Penelitian ini dilakukan di Kecamatan Poncokusumo dengan pertimbangan bahwa di Kecamatan Poncokusumo Kabupaten Malang merupakan sentra produksi Apel terbesar di Kabupaten Malang. Penelitian dilakukan selama 7 bulan mulai bulan Maret sampai dengan bulan September 2014.

Subjek penelitian ini adalah petani apel di wilayah Kecamatan Poncokusumo yang telah melakukan budidaya apel selama 10 
tahun atau lebih dan masih berusaha apel sampai saat ini. Obyek penelitian adalah perubahan iklim dengan unsur-unsur yang akan menjadi kajian meliputi suhu, kelembaban dan curah hujan serta bentuk adaptasi yang dilakukan para petani.

Populasi penelitian ini adalah petani apel yang ada di Kecamatan Poncokusumo Kabupaten Malang berjumlah 665 orang yang tersebar dalam 4 desa yaitu Poncokusumo dengan jumlah petani sebanyak 277 orang, Ringinanom 113 orang, Pandansari 128 orang dan Gubuk Klakah 147 orang. Dengan menggunakan teknik sampel proporsional, maka jumlah sample yang diambil dari desa Poncokusumo sebanyak 2,45 kali jumlah sampel dari desa Ringinanom, 2,16 kali desa Pandansari dan 1,88 kali desa Gubuk Klakah.

Sampel yang ditentukan untuk desa Poncokusumo adalah $10 \%$ dari populasi sehingga jumlah sampel 28 orang, dengan demikian untuk desa Ringinanom jumlah sampel 11 orang, desa Pandansari 13 orang dan desa Gubuk Klakah 16 orang. Total jumlah sampel secara keseluruhan dalam penelitian ini adalah 68 orang.

Instrumen penelitian diuji menggunakan uji validitas dan reliabilitas terlebih dahulu sebelum digunakan. Sedangkan data hasil penelitian diuji dengan analisis regresi linier berganda untuk mengetahui peran masingmasing unsur terhadap produktivitas apel. Bentuk adaptasi petani dianalisis secara deskriptif.

\section{HASIL DAN PEMBAHASAN Karakteristik Umum Responden}

Petani apel yang menjadi responden dalam penelitian ini $100 \%$ berjenis kelamin pria, karena pada umumnya kegiatan usaha Apel di Desa Poncokusumo dilakukan oleh pria. Responden dalam penelitian ini memiliki tingkat usia yang berbeda-beda. Rentang usia responden sebagian besar berada pada tingkat usia 40 - 49 tahun yaitu sebanyak 38,24\%. Responden sebanyak $20,58 \%$ berada pada tingkat usia 30-39 tahun dan 22,07\% berada pada tingkat usia $50-59$ tahun. Sedangkan sisanya sebanyak $10,29 \%$ berada pada rentang usia 20 - 29 tahun dan $8,82 \%$ berusia 60 tahun ke atas. Hal ini menunjukkan bahwa mayoritas responden berada dalam usia produktif.

Tingkat pendidikan responden sangat bervariasi dengan prosentase responden yang memiliki pendidikan SD sebanyak 30,88\%, berpendidikan SMP sebanyak 19,12\%, berpendidikan SMA sebanyak 41,18\%, berpendidikan perguruan tinggi sebanyak $5,88 \%$ dan $2,94 \%$ sisanya berpendidikan pesantren. Beragamnya pendidikan petani apel di kecamatan Poncokusumo ini disebabkan kondisi ekonomi keluarga yang relatif mampu untuk melanjutkan jenjang pendidikan yang lebih tinggi. Karena petani apel pernah merasakan kejayaan hasil panennya pada dekade 1985 sampai 1995.

Variasi kepemilikan luas lahan responden berkisar antara 0,01-3 hektar. Responden yang melakukan kegiatan usaha apel pada lahan kurang dari 0,25 hektar mencapai $13,24 \%$ dan yang bertani pada lahan antara 0,25-0,5 hektar sebanyak 58,83\%, sedangkan petani yang melakukan kegiatan usahatani pada lahan lebih dari 0,51 hingga satu hektar adalah sebanyak $20,58 \%$ dan sisanya yaitu sebanyak $7,35 \%$ petani apel bertani pada lahan lebih dari satu hektar

\section{Produktivitas Apel di Daerah Penelitian}

Wilayah Poncokusumo identik dengan apel, karena merupakan sentra apel terbesar di Malang Raya. Jenis apel yang mayoritas diusahakan di daerah ini adalah apel manalagi dan rome beauty atau yang banyak dikenal dengan sebutan apel batu. Data perkembangan produksi apel di Poncokusumo dapat dilihat dalam Tabel.1.

Berdasarkan tabel di atas terlihat bahwa jumlah pohon apel dari tahun 1998 sampai tahun 2002 mengalami peningkatan. Pada tahun 2003 mulai terjadi penurunan sampai tahun 2010. Bahkan pada tahun 2011 terjadi penurunan jumlah pohon sampai dengang $12 \% \mathrm{~T}$. Rata-rata jumlah pohon per tahun selama 14 tahun tersebut adalah 1.247.042,78 pohon, sedangkan jumlah pohon berbuah mengalami fluktuasi jumlah dan terjadi peningkatan tajam pada tahun 2004 dari 120.000 pohon menjadi 1.266 .432 pohon. Tahun 2007 terjadi penurunan jumlah pohon 
berbuah sampai dengan $32 \%$, sedangkan tahun 2008 mengalami kenaikan yang berfluktuasi sampai tahun 2010. Tahun 2011 penurunan jumlah pohon sangat signifikan yaitu sebesar $47 \%$. Rata-rata pohon berbuah per tahun selama 14 tahun terakhir adalah 757.156,93 pohon. Ini berarti rata-rata pohon berbuah per tahun adalah $60,716 \%$ dari rata-rata jumlah pohon yang ada.

Rata-rata produksi apel per tahun selama 14 tahun terakhir adalah 606.267,14 kwintal dengan produktivitas $66,16 \mathrm{~kg}$ per pohon. Rata-rata produksi apel sangat fluktuatif dari tahun ke tahun. Namun produksi terbesar terjadi pada tahun 2006 yaitu sebesar 2.008.953 kwintal. Sedangkan produktivitas tertinggi terjadi pada tahun 2011 sebesar 2,541704194 kwintal per pohon.

Tabel 1. Produksi dan Produktivitas apel di Kecamatan Poncokusumo tahun $1998-2011$.

\begin{tabular}{lcc}
\hline Tahun & $\begin{array}{c}\text { Produksi } \\
\text { kwintal) }\end{array}$ & $\begin{array}{l}\text { Produktivitas } \\
\text { kw/pohon) }\end{array}$ \\
\hline 1998 & 10.340 & 0,05403089 \\
1999 & 116.897 & 0,16000005 \\
2000 & 2.080 & 0,26733333 \\
2001 & 66.250 & 0,20384615 \\
2002 & 84.820 & 0,19814192 \\
2003 & 33.845 & 0,28204166 \\
2004 & 987.817 & 0,78000003 \\
2005 & 1.487 .581 & 1,13537514 \\
2006 & 2.008 .953 & 1,55577695 \\
2007 & 548.077 & 0,62613471 \\
2008 & 527.514 & 0,43568688 \\
2009 & 697.536 & 0,69142175 \\
2010 & 370.577 & 0,32909842 \\
2011 & 1.505 .453 & 2,54170419 \\
\hline Jumlah & 8.487 .740 & 9,2606 \\
Rata2 & $606.267,14$ & 0,6616 \\
\hline & & \\
\hline
\end{tabular}

Sumber : Data Sekunder dari Dinas Pertanian Kabupaten Malang tahun 2013

Tren produktivitas apel di Kecamatan Poncokusumo dari tahun 1998 sampai tahun 2011 seperti Gambar berikut :

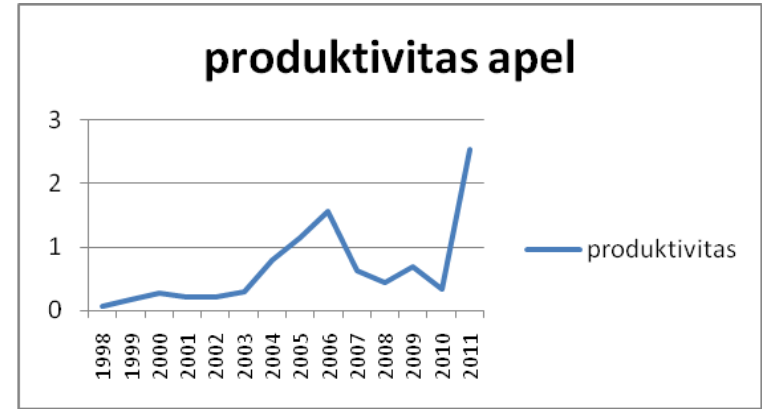

Gambar 1. Tren produktivitas apel di Kecamatan Poncokusumo tahun 1998 - 2011

\section{Kondisi Iklim di Daerah Penelitian}

Wilayah Kecamatan Poncokusumo termasuk daerah dataran tinggi dengan hawa sejuk sehingga sangat baik untuk pertumbuhan apel. Selama kurun waktu 14 tahun terakhir terjadi fluktuasi unsur-unsur iklim dengan ratarata seperti pada Tabel.9.

\begin{tabular}{|c|c|}
\hline Unsur Iklim & Rata-rata/thn \\
\hline Suhu & $23,833^{\circ} \mathrm{C}$ \\
\hline Curah hujan & $1966,5(\mathrm{~mm})$ \\
\hline Kelembaban & $82 \%$ \\
\hline
\end{tabular}

Sumber: BMKG Karangploso Malang tahun 2013

Tabel di atas menunjukkan bahwa rata-rata suhu tahunan selama 14 tahun terakhir adalah $23,83^{\circ} \mathrm{C}$. Curah hujan tahunan dengan rata-rata $1966,5 \mathrm{~mm}$ per tahun dan kelembaban rata-rata $82 \%$.

\section{Dampak Perubahan Iklim Terhadap Produktivitas Tanaman Apel}

Tanaman apel bukan merupakan tanaman asli Indonesia melainkan berasal dari daerah Asia Barat yang beriklim sub tropik. Oleh karena itu dalam pengembangan budidayanya di Indonesia yang beriklim tropis membutuhkan syarat-syarat tertentu agar dapat tumbuh dan berproduksi secara optimal. Ketinggian tempat, media tanam dan iklim merupakan persyaratan utama untuk budidaya apel di Indonesia (Prihatman, 2000). Iklim sebagai salah satu syarat tumbuh tanaman apel, 
dituntut agar selalu dalam kondisi yang optimal. Perubahan iklim yang ekstrem dapat mengganggu produktivitas tanaman apel, bahkan sampai pada kematian tanaman. Jika salah satu syarat tersebut tidak terpenuhi, maka pertumbuhan apel tidak akan optimal. Berdasarkan hasil analisis pengaruh suhu, curah hujan dan kelembaban terhadap produktivitas tanaman apel adalah sebagai berikut :

Tabel 3. Koefisien Regresi

\begin{tabular}{|c|c|c|c|c|}
\hline & Coefficients & $\begin{array}{c}\text { Standard } \\
\text { Error }\end{array}$ & $t$ Stat & \\
\hline Intercept & 61,16980813 & 46,75933843 & 1,308183781 & \\
\hline LogX Var1 & 18,55364541 & 16,81590173 & $-1,10333931$ & \\
\hline $\begin{array}{l}\text { LogX Var2 } \\
\text { LogX Var } \\
3\end{array}$ & $\begin{array}{r}5,043489996 \\
2,291233269\end{array}$ & $\begin{array}{l}1,945987923 \\
17,51502744\end{array}$ & $\begin{array}{l}2,591737562 \\
0,130815283\end{array}$ & \\
\hline Sumber: Da & primer diolc & & & \\
\hline $\begin{array}{l}\text { Berdasarl } \\
\text { didapatka } \\
\text { berikut: } \\
\text { Log Y } \\
5,0435) \mathrm{L} \\
\text { dengan : } \\
\text { LogY = } \\
\text { LogX1 = } \\
\operatorname{LogX} 2= \\
\operatorname{LogX} 3=\end{array}$ & $\begin{array}{l}\text { n hasil } \\
\text { persam } \\
61,16 \\
\mathrm{X} 2+2,2 \\
\text { roduksti } \\
\text { Suhu } \\
\text { Curah H } \\
\text { Kelemba }\end{array}$ & $\begin{array}{l}\text { regresi } \\
n \text { regre } \\
+\quad(-18, \\
1 \log X 3\end{array}$ & $\begin{array}{l}\text { ada ta } \\
\text { linier } \\
\text { 4) } \log X\end{array}$ & $\begin{array}{l}\text { bagai } \\
+\quad(-\end{array}$ \\
\hline
\end{tabular}

Tabel 4. Hasil Uji Serempak (Uji F) ANOVA

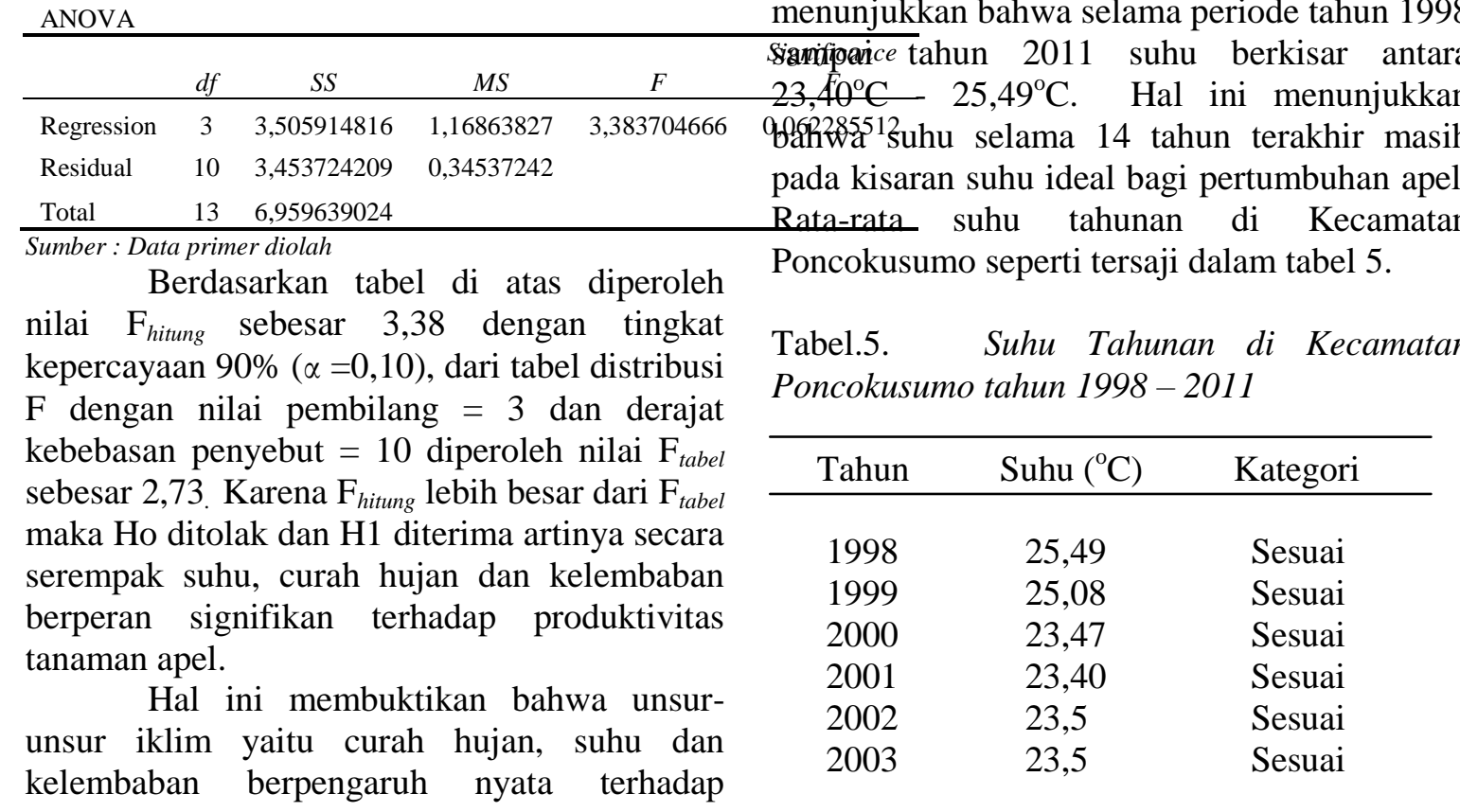

produktivitas tanaman apel di Kecamatan Poncokusumo. Artinya jika ketiga unsur iklim tersebut mengalami perubahan ekstreme secara bersama-sama, maka akan mempengaruhi produktivitas apel.

\section{Pengaruh Suhu Terhadap Produktivitas Tanaman Apel}

Agar dapat tumbuh secara optimal, tanaman apel membutuhakan suhu yang sesuai pada kisaran $16-27^{\circ} \mathrm{C}$. Suhu tinggi akan mengakibatkan terjadinya penguapan pada tanaman sehingga menyebabkan tanaman mengalami kekeringan dan kerontokan daun. ${ }^{9}$ Apalagi tanaman apel mempunyai perakaran yang dangkal, sehingga membutuhkan ketersediaan air di permukaan tanah. Apabila permukaan tanah mengalami kekeringan, maka penyerapan air oleh akar akan terganggu sehingga pertumbuhan tanaman apel akan terganggu pula, yang pada akhirnya berpengaruh pada produksi buah.

Hasil analisis uji t (tabel 10) diperoleh bahwa variabel $\log \mathrm{X} 1$ (suhu) nilai $\mathrm{t}_{\text {hitung }}$ sebesar $-1,103$ dengan tingkat kepercayaan 90\% $(\alpha=$ $0.10)$, derajat bebas $(\mathrm{df}=10)$ dari tabel distribusi $\mathrm{t}$ diperoleh nilai $\mathrm{t}_{\text {tabel }}$ sebesar 1,372. Karena $\mathrm{t}_{\text {hitung }}$ lebih kecil dari $\mathrm{t}$ tabel maka dapat dikatakan bahwa variabel suhu (log X1) tidak berperan signifikan terhadap produktivitas apel.

Hasil pantauan BMKG Karangploso menunjukkan bahwa selama periode tahun 1998 Sianifipaice tahun 2011 suhu berkisar antara $25,49^{\circ} \mathrm{C}$. Hal ini menunjukkan Rata-rata suhu tahunan di Kecamatan Tabel.5. Suhu Tahunan di Kecamatan han apel. 


\begin{tabular}{lcc}
2004 & 23,43 & Sesuai \\
2005 & 23,74 & Sesuai \\
2006 & 23,51 & Sesuai \\
2007 & 23,4 & Sesuai \\
2008 & 23,3 & Sesuai \\
2009 & 23,7 & Sesuai \\
2010 & 23,9 & Sesuai \\
2011 & 24,01 & Sesuai \\
& & \\
\hline Jumlah & 333,66 & \\
Rata-rata & 23,83 & \\
\hline
\end{tabular}

Sumber : BMKG Karangploso Tahun 2013

\section{Pengaruh Curah Hujan Terhadap Produksi Tanaman Tanaman Apel}

Selama pertumbuhannya, tanaman apel membutuhkan pengairan yang memadai sepanjang musim. Pada saat musim penghujan, kebutuhan air dapat terpenuhi dengan baik, tetapi perlu diperhatikan agar tanaman apel tidak sampai terendam air.

Hasil analisis uji t (tabel 10) diperoleh bahwa variabel $\log \mathrm{X} 2$ (curah hujan) nilai $\mathrm{t}_{\text {hitung }}$ sebesar -2,592 dengan tingkat kepercayaan $90 \%$ $(\alpha=0.10)$, derajat bebas $(\mathrm{df}=10)$ dari tabel distribusi $\mathrm{t}$ diperoleh nilai $\mathrm{t}_{\text {tabel }}$ sebesar 1,372. Karena $\mathrm{t}_{\text {hitung }}$ lebih kecil dari $\mathrm{t}_{\text {tabel }}$ maka dapat dikatakan bahwa variabel curah hujan $(\log \mathrm{X} 1)$ berperan signifikan terhadap produktivitas apel.

Curah hujan yang ideal untuk pertumbuhan tanaman apel adalah 1.000-2.600 $\mathrm{mm} /$ tahun dengan hari hujan 110-150 hari/tahun. Dalam setahun banyaknya bulan basah adalah 6-7 bulan dan bulan kering 3-4 bulan (Prihatman, 2000). Namun dengan adanya perubahan iklim jumlah bulan basah dan bulan kering sulit diprediksi jumlahnya. Rata-rata curah hujan tahunan selama 14 tahun terakhir di kecamatan Poncokusumo seperti dalam Tabel 13.

Berdasarkan data dari BMKG Karangploso, rata-rata curah hujan adalah 1966,5 mm/tahun. Walaupun curah hujan tersebut masih dalam batas kisaran curah hujan ideal untuk pertumbuhan tanaman apel, namun sudah berada pada kisaran yang tinggi.. Ratarata curah hujan tahunan di Kecamatan Poncokusumo pada tahun 1998 sampai tahun 2004 melebihi $2.600 \mathrm{~mm} / \mathrm{tahun}$ kecuali tahun
2003 berada pada titik $2.453 \mathrm{~mm} / \mathrm{tahun}$. Pada tahun 2005 sampai dengan tahun 2009 curah hujan berada pada kisaran curah hujan yang ideal untuk pertumbuhan apel. Namun pada tahun 2010 kembali terjadi peningkatan curah hujan sampai $2.954 \mathrm{~mm} /$ tahun melebihi batas maksimal curah hujan ideal. Kemudian kembali sesuai pada tahun 2011.

Curah hujan yang tinggi akan mengganggu pertumbuhan maupun produksi tanaman apel terutama saat pembungaan karena akan menyebabkan bunga gugur tidak dapat menjadi buah sehingga berpengaruh pada jumlah produksi buah yang dihasilkan (Prihatman, 2000). Hal ini terbukti dari hasil penelitian, bahwa responden yang menyatakan curah hujan yang tinggi pada saat pembungaan menyebabkan terjadinya bunga gugur sebesar 62 orang atau 91,18\% dari selruh responden, sedangkan sisanya 8 orang menyatakan bahwa tidak menyebabkan bunga gugur. Hasil wawancara dengan responden, bahwa gugurnya bunga akibat hujan yang terjadi pada saat pembungaan dapat mencapai 50\%. Ini berarti bahwa petani apel akan kehilangan hasil panennya sebesar 50\% dari seharusnya. Namun jika hujan terjadi bukan pada saat pembungaan, maka resiko kehilangan hasil menjadi lebih kecil.

Tabel. 6. Curah Hujan Tahunan Di Kecamatan Poncokusumo Tahun1998-2011

\begin{tabular}{ccc}
\hline Tahun & $\begin{array}{c}\text { Curah Hujan } \\
(\mathrm{mm} / \mathrm{thn})\end{array}$ & Kategori \\
\hline 1998 & 2.711 & Tinggi \\
1999 & 2.617 & Tinggi \\
2000 & 3.554 & Tinggi \\
2001 & 2.849 & Tinggi \\
2002 & 2.694 & Tinggi \\
2003 & 2.453 & Sesuai \\
2004 & 2.735 & Tinggi \\
2005 & 2.168 & Sesuai \\
2006 & 2.058 & Sesuai \\
2007 & 1.790 & Sesuai \\
2008 & 1.896 & Sesuai \\
2009 & 2.117 & Sesuai \\
2010 & 2.954 & Tinggi \\
2011 & 1.965 & Sesuai \\
\hline Jumlah & 27531 & \\
Rata-rata & 1966,5 & \\
& &
\end{tabular}




\section{Sumber : BMKG Karangploso Malang tahun 2013}

Pengaruh Kelembaban Terhadap Produksi Tanaman Apel

Kelembaban udara yang dikehendaki tanaman apel sekitar $75 \%$ - 85\%. Hasil wawancara dengan responden menyatakan bahwa jika kelembaban terlalu tinggi, akan menyebabkan serangan penyakit pada tanaman apel. Hal ini terjadi karena kelembaban tinggi sangat optimal untuk pertumbuhan jamur penyebab penyakit pada tanaman apel. Penyakit pada tanaman apel dapat menyerang beberapa bagian tanaman seperti daun, batang, bunga dan buah.

Serangan pada daun akan menyebabkan cacar daun, mengering, kemudian gugur. Bunga yang terserang penyakit akan mengalami pembusukan dan rontok. Batang yang terserang penyakit akan membusuk dan lama-lama kering. Sedangkan serangan pada buah akan menyebabkan buah busuk dan rontok (Prihatman, 2000).

Serangan hama dan penyakit akibat kelembaban dapat dikendalikan dengan penyemprotan pestisida secara intensif. Pada umumnya petani menyemprot perstisida secara rutin 5-7 hari sekali, walaupun tanaman apel tidak terserang hama maupun penyakit. Hal ini dilakukan sebagai tindakan preventif terhadap serangan yang kemungkinan timbul, karena apel sangat rentan terhadap serangan hama dan penyakit.

Hasil analisis uji t (tabel 10) diperoleh bahwa variabel log X1 (kelembaban) nilai $\mathrm{t}_{\text {hitung }}$ sebesar 0,131 dengan tingkat kepercayaan $90 \%$ $(\alpha=0.10)$, derajat bebas ( $\mathrm{df}=10)$ dari tabel distribusi $\mathrm{t}$ diperoleh nilai $\mathrm{t}_{\text {tabel }}$ sebesar 1,372 . Karena $t_{\text {hitung }}$ lebih kecil dari $t_{\text {tabel }}$ dapat dikatakan bahwa variabel kelembaban $(\log$ X1) tidak berperan signifikan terhadap produktivitas apel.
Tabel.7. Kelembaban Rata-rata Tahunan di Kecamatan Poncokusumo Tahun $1998-2011$

\begin{tabular}{ccl}
\hline Tahun & Kelembaban $(\%)$ & Kategori \\
\hline 1998 & 85 & Sesuai \\
1999 & 83 & Sesuai \\
2000 & 78,92 & Sesuai \\
2001 & 82,17 & Sesuai \\
2002 & 80,67 & Sesuai \\
2003 & 81,75 & Sesuai \\
2004 & 82,08 & Sesuai \\
2005 & 81,92 & Sesuai \\
2006 & 78,75 & Sesuai \\
2007 & 83,67 & Sesuai \\
2008 & 82,5 & Sesuai \\
2009 & 81,33 & Sesuai \\
2010 & 86,5 & Tinggi \\
2011 & 79,58 & Sesuai \\
\hline Jumlah & & 1148,0 \\
Rata-rata & & 82,0 \\
\hline
\end{tabular}

Sumber : BMKG Karangploso Tahun2013

Berdasarkan data rata-rata kelembaban tahunan dari BMKG Karangploso, terlihat bahwa kelembaban udara di wilayah kecamatan Poncokusumo mulai tahun 1998 sampai dengan 2009 berkisar antara 78,75\% -85\%. Ini berarti kelembaban di wilayah ini cukup ideal untuk pertumbuhan tanaman apel secara optimal. Namun terjadi peningkatan kelembaban pada tahun 2010 yaitu $86 \%$ melampaui batas maksimal kisaran suhu optimal untuk pertumbuhan tanaman apel. Tahun 2011 kelembaban kembali normal pada kisaran kelembaban yang ideal untuk pertumbuhan apel.

\section{Adaptasi Responden Terhadap Perubahan Iklim}

Perubahan iklim dan segala dampaknya bagi petani apel baik langsung maupun tidak langsung, menyebabakan petani perlu mengambil tindakan agar kelangsungan usaha pertaniannya tetap dapat berlangsung. Tindakan tersebut adalah dengan beradaptasi terhadap perubahan iklim. Adaptasi adalah sebuah sistem untuk menanggulangi situasi eksternal yang gawat sehingga sistem harus menyesuaikan dengan lingkungannya. 
Lingkungan eksternal dalam hal ini adalah terjadinya perubahan iklim yang mengancam kelangsungan usaha apel. Hasil penelitian membuktikan bahwa $85,29 \%$ responden melakukan adaptasi. Sedangkan $14,71 \%$ responden tidak melakukan adaptasi.

Upaya adaptasi responden untuk mengatasi suhu ekstrem adalah dengan melakukan penyiraman. Umumnya petani menyiram tanaman apel pada musim kemarau yang panjang untuk menghindari kekeringan. Penyiraman dilakukan pada pagi hari atau sore hari.

Adaptasi petani terhadap curah hujan yang tinggi adalah dengan menyemprot pestisida dengan interval waktu yang lebih pendek. Berdasarkan hasil wawancara diperoleh bahwa penyemprotan pestisida dilakukan lebih sering untuk mencegah dan mengurangi kerontokan bunga yang berlebihan, serta menjaga agar tanaman tidak terserang hama maupun penyakit akibat kelembaban tinggi karena curah hujan yang tinggi pula.

Salah satu upaya responden dalam beradaptasi terhadap perubahan kelembaban adalah dengan melakukan pemangkasan cabang lebih banyak. Pada budidaya apel, pemangkasan produksi rutin dilakukan untuk menstimulasi pembentukan bunga. Pemangkasan produksi sangat menentukan jumlah bunga yang akan muncul. Selain itu dilakukan pula pemangkasan cabang, yaitu pemangkasan terhadap cabag-cabang yang kering atau terserang penyakit yang tidak dapat berproduksi lagi. Namun pada kondisi perubahan iklim dengan curah hujan tinggi, yang memicu peningkatan kelembaban dan terjadinya kabut, pemangkasan cabang dilakukan lebih intensif. Meskipun cabangcabang tersebut masih produktif, tetapi jika dirasa kanopi pohon masih terlalu rimbun, maka cabang-cabang tersebut akan dipangkas. Tujuannnya adalah untuk mengurangi kelembaban agar dapat meminimalisir timbulnya serangan penyakit. Hasil penelitian menunjukkan bahwa dari 58 orang yang melakukan adaptasi $60,34 \%$ responden melakukan dengan cara pemangkasan cabang secara intensif, sedangkan sisanya tidak.
Bentuk adaptasi yang lain adalah pola tanam secara tumpangsari. Komoditas yang digunakan untuk tumpangsari adalah sayuran dan bunga hias. Berdasarkan hasil wawancara dengan responden, pola tumpangsari dilakukan sebagai sumber pendapatan alternatif akibat penurunan hasil panen apel mereka. Di samping cara budidayanya lebih mudah, lebih cepat panen dan lebih tahan terhadap perubahan iklim, penyemprotan pestisida tidak perlu dilakukan karena pada saat penyemprotan untuk apel, secara otomatis komoditas tumpangsari ikut tersemprot juga. Dengan demikian biaya pestisida dapat dihemat. Hasil penelitian menunjukkan bahwa 14 orang responden $(24,14 \%)$ melakukan tumpangsari dan selebihnya 44 responden $(75,86 \%)$ tidak melakukan. Besarnya responden yang tidak melakukan adaptasi dengan pola tumpangsari disebabkan pemahaman mereka bahwa sistem tumpangsari justru akan merusak perakaran tanaman apel, sehingga akan lebih merugikan bagi mereka. Para petani tidak mau mengambil resiko tersebut.

\section{KESIMPULAN DAN SARAN \\ Kesimpulan}

Berdasarkan hasil penelitian yang dilakukan maka dapat diambil kesimpulan bahwa :

Unsur-unsur iklim yang meliputi suhu, curah hujan dan kelembaban secara serempak berperan signifikan terhadap produktivitas tanaman apel, namun secara terpisah hanya unsur curah hujan yang berperan signifikan terhadap produktivitas apel. Sebagian besar Petani melakukan adaptasi terhadap perubahan iklim yaitu sebesar $85,29 \%$. Adaptasi yang dilakukan petani antara lain adalah penyiraman tanaman untuk mengatasi suhu tinggi yang ekstrim, tumpangsari untuk mengatasi penurunan pendapatan dari usaha apel, pengurangan cabang lebih banyak untuk mengatasi kelembaban dan penyemprotan pestisida lebih intensif untuk mengatasi timbulnya penyakit akibat curah hujan dan kelembaban tinggi. 
Saran

Perlu diteliti lebih lanjut mengenai faktor-faktor sosial ekonomi yang mempengaruhi adaptasi petani serta bentuk adaptasi manakah yang paling sesuai dan paling baik untuk mengatasi perubahan iklim saat ini. Bagi pengambil kebijakan, perlu adanya perhatian khusus terutama terkait masalah mahalnya harga saprodi untuk pemeliharaan apel, kenaikan harga apel yang tidak sebanding dengan harga saprodi, dan pembinaan kepada kelompok tani yang lebih intensif.

\section{DAFTAR PUSTAKA}

Ainun, Y. 2010. Cuaca Tak Menentu, Petani Apel Merugi. http://www.beritajatim.com/detailnews.p hp/1/Ekonomi/2010-08-

18/74417/Cuaca_Tak_Menentu,_Petani_ Apel_Merugi. Diunduh 20 Januari 2011.

Anonim, 2007. Strategi dan Inovasi Teknologi Pertanian Menghadapi Perubahan Iklim Global. Dipublikasikan oleh Badan Penelitian dan Pengembangan Pertanian. Departemen pertanian

Anonim, 2008. Dampak Perubahan Iklim Terhadap Sektor Pertanian, Serta Strategi Antisipasi dan Teknologi Adaptasi. Pengembangan Inovasi Pertanian 1(2):138-140

Anonim, 2011. Pengembangan Apel Tropis di Indonesia.

http://foragri.blogsome.com/pengemba ngan-apel-tropis-di-indonesia/.

Diunduh 3 Oktober 2011.

Ariyanto,S.E. 2010. Kajian Dampak Perubahan Iklim Terhadap Produktivitas Kacang Hijau (Phaseolus radiatus l.) di Lahan Kering. Jurnal ISSN : 1979-6870.

Haeruman ,H. 2009. Perspektif Kebijakan Terkait perubahan Iklim dan Dampaknya Terhadap Ekonomi. Jurnal Ekonomi Lingkungan. Vol.13/No.1/2009.

Irianto, G. 2009. Antisipasi Litbang Serealia Dalam Menghadapi Dampak Pemanasan Global Guna Mendukung Kemandirian Pangan. Prosiding
Seminar Nasional Serealia 2009. ISBN :978-979-8940-27-9.

Nasrullah, 2011. Perubahan Iklim dan Trend Data Iklim. Bidang Informasi Perubahan Iklim BMKG.

Mumpuni,G.N. 2009. Analisis Kelayakan Finansial dan Sebsitivitas Usaha Tanaman Apel di Malang Raya. Publikasi Ilmiah. Lembaga Penelitian. Universitas Muhammadiyah Malang.

Pasaribu, M.S dkk, 2008. Peningkatan Kapasitas Adaptasi Petani di Daerah Marginal Terhadap Perubahan Iklim. Laporan Akhir Penelitian. Pusat Analisis Sosial Ekonomi dan Kebijakan Pertanian. Departemen Pertanian.

Prihatman, K. 2000. Apel (Malus Sylvestris ). Sistim Informasi Manajemen Pembangunan di Perdesaan. BAPPENAS.

Purwanti, S. 2003. Pemasaran Buah apel di Dalam Negeri. http://cybex.deptan.go.id/penyuluhan/p emasaran-buah-apel-di-dalam-negeri-0. Diunduh 2 Januari 2012.

Setyawan A, 2011. Apel Bisa menghilang dari Malang. Kompas.com. Diunduh 7 April 2011.

Sunarjono, H. 2003. Ilmu Produksi Tanaman dan Buah-buahan. Penebar Swadaya. Jakarta.

Susandi, A. 2005. Bencana Perubahan Iklim Global dan Proyeksi Perubahan Iklim Indonesia. Jurnal Teknik Lingkungan. Oktober 2005. ITB. Bandung.

Surmaini, E. dkk. 2011. Upaya Sektor Pertanian Dalam Menghadapi Perubahan Iklim. Jurnal Litbang Pertanian 30(1),2011.

Trisno, I. 2011. Dampak Perubahan Iklim Terhadap Produksi Tanaman Pangan. Hasil Dewan Riset Daerah Kantor Penelitian dan Pengembangan Kabupaten Pati. http://litbang.patikab.go.id/index.php?o ption=com_content $\&$ view $=$ article $\&$ id $=$ 111:dampak-perubahan-iklimterhadap-produksi-tanamanpangan\&catid=124: dampakperubahan-iklim-terhadap-produksi- 
tanaman-pangan \&Itemid=109.

Diunduh 27 Oktober 2011.
World Bank, 2010. Adaptasi Terhadap Perubahan Iklim. Policy Brief. World Bank. 